\title{
The Effects of Power Characteristics on the Heat Transfer Process in Various Types of Motionless Mixing Devices
}

\author{
Rafał Rakoczy, Marian Kordas and Stanisław Masiuk
}

Additional information is available at the end of the chapter

http://dx.doi.org/10.5772/52170

\section{Introduction}

Mixing is probably the most frequently used chemical engineering operation in industry. It should be noticed that a good quality of mixing is generally very difficult to achieve. Static mixers, also known as motionless mixers, are usually applied in various types of chemical engineering fields. In recent decades, static mixers have been found in a wide range of industries. These mixers are designed to mix fluids without any recourse to a the mechanical motion and static mixers may be used as an alternative to mechanical agitators. A motionless mixer is a specially designed geometrical structure of different shapes and forms of the elements inserted in a long pipe. The number of elements and the type of a mixing device both depend on the mixing degree in any applications and a wide range of tasks. A static mixer consists of a contacting device with a series of internal stationary mixing elements of a specific geometry, inserted in a pipe. By using a specific geometrical combination of these elements one-after-another, the additional turbulence of the flowed fluid contributes to the improvement of mixing efficiency.

The benefits of a static mixer include low operating and maintenance costs. Morever, it needs little place, no mechanical seals, it is self-cleaning and low shear forces prevent excessive stressing of the product especially in bio-processes. By using a static mixer it is easy to control the output product quality. Furthermore, static mixers are characterized by the low energy consumption and an easy usage and installation.

The use of static mixers as alternative mixing devices for various fluids has been analysed in many scientific researches (Ruivo et al., 2006; Regner et al., 2005). Static mixers are nowadays used in many chemical processes as in-line contacting devices for gases and liquids. Typical applications range from the reactor in polymer systems (Fourcade et al., 2001), heat or mass transfer alternative devices (Simões et al., 2008), mixing liquid-liquid systems in the laminar or turbulent flow (Rama Rao et al., 2007) to intensifying gas-liquid mass transfer processes (Al 
Taweel et al., 2005). Moreover, static mixers have a wide range of applications, such as continuous mixing, chemical reactors or mass and heat transfer processes or a thermal homogenization (Li et al., 1996; Visser et al., 1999; Lemenand et al., 2010). Several theoretical and experimental studies of the pressure drop are presented in (Liu et al., 2006; Engler et al., 2004; Hobbs et al., 1998; Kumar et al., 2008; Li et al., 1997; Joshi et al., 1995). The applications of static mixers to improve the heat transfer can be divided into the thermal homogenization (in many cases coupled with the compositional homogenization), a pure heat transfer in heat exchangers and a combined heat transfer with chemical reactions (Thakur et al., 2003).

In the case of the mixing operation, the pressure drop is used as a pertinent criterion to highlight the differences between various types of static mixers. This parameter is very common to all applications of static mixers. As follows form the literature (Thakur et al., 2003) the key parameter for the heat transfer process in static mixers is the Nusselt number. Azer and Lin defined the parameter which takes the heat transfer enhancement and the pressure drop increase into consideration (Thakur et al., 2003).

The main objective of the present work is to propose a new criterion for the selection of a static mixer in heat transfer experiments. This parameter is taking into account the hydrodynamic behaviour of the flow in a static mixer by using the fluid mechanic equations. Additionally, the proposed criterion is applied to the various types of static mixers (EMI, Ross, Komax and the patented construction of the static mixer (Masiuk \& Szymański, 1997).

\section{Theoretical background}

The mathematical description of heat transfer operations in tubular static mixers is given by the energy equation. For a steady flow of an incompressible fluid with constant or averaged transport properties or physical parameters it gives

$$
\rho c_{p}\left(\frac{\partial T}{\partial t}+\bar{w} \operatorname{grad} T\right)=-T\left(\frac{\partial p}{\partial T}\right)_{V} \operatorname{div} \bar{w}+\operatorname{div}(k \operatorname{grad} T)+\frac{d p}{d t}+\Phi_{V}
$$

In the cylindrical coordinate system $(r, \theta, z)$, Eq.(1) can be rewritten in the equivalent form

$$
\begin{aligned}
& \rho c_{p}\left[\begin{array}{l}
\frac{\partial T(t ; r, \theta, z)}{\partial t}+ \\
+\left(w_{r} \overline{e_{r}}+w_{\theta} \overline{e_{\theta}}+w_{z} \overline{e_{z}}\right)\left(\frac{\partial T(t ; r, \theta, z)}{\partial r} \overline{e_{r}}+\frac{1}{r} \frac{\partial T(t ; r, \theta, z)}{\partial \theta} \overline{e_{\theta}}+\frac{\partial T(t ; r, \theta, z)}{\partial z} \overline{e_{z}}\right)
\end{array}\right]= \\
& =-T(t ; r, \theta, z)\left(\frac{\partial p(t ; r, \theta, z)}{\partial T}\right)_{V}\left(\frac{1}{r} \frac{\partial\left(r w_{r}\right)}{\partial r}+\frac{1}{r} \frac{\partial w_{\theta}}{\partial \theta}+\frac{\partial w_{z}}{\partial z}\right)+ \\
& +k\left[\frac{1}{r} \frac{\partial}{\partial r}\left(r \frac{\partial T(t ; r, \theta, z)}{\partial r}\right)+\frac{1}{r^{2}} \frac{\partial^{2} T(t ; r, \theta, z)}{\partial \theta^{2}}+\frac{\partial^{2} T(t ; r, \theta, z)}{\partial z^{2}}\right]+\frac{\partial p(t ; r, \theta, z)}{\partial t}+ \\
& +\left(w_{r} \overline{e_{r}}+w_{\theta} \overline{e_{\theta}}+w_{z} \overline{e_{z}}\right)\left(\frac{\partial p(t ; r, \theta, z)}{\partial r} \overline{e_{r}}+\frac{1}{r} \frac{\partial p(t ; r, \theta, z)}{\partial \theta} \overline{e_{\theta}}+\frac{\partial p(t ; r, \theta, z)}{\partial z} \bar{e}_{z}\right)+\Phi_{V}
\end{aligned}
$$


In the above Eq.(2), the viscous dissipation function, $\Phi_{V}$, may be expressed as follows

$$
\begin{gathered}
\Phi_{V}=2 \eta\left[\left(\frac{\partial w_{r}}{\partial r}\right)^{2}+\left(\frac{1}{r} \frac{\partial w_{\theta}}{\partial \theta}+\frac{\partial w_{r}}{\partial r}\right)^{2}+\left(\frac{\partial w_{z}}{\partial z}\right)^{2}\right]+ \\
+\eta\left\{\left[r \frac{\partial}{\partial r}\left(\frac{w_{\theta}}{r}\right)+\frac{1}{r} \frac{\partial w_{r}}{\partial \theta}\right]^{2}+\left[\frac{1}{r} \frac{\partial w_{z}}{\partial \theta}+\frac{\partial w_{\theta}}{\partial z}\right]^{2}+\left[\frac{\partial w_{r}}{\partial z}+\frac{\partial w_{z}}{\partial r}\right]^{2}\right\}+ \\
+\left(\eta_{V}-\frac{2}{3} \eta\right)\left[\frac{1}{r} \frac{\partial\left(r w_{r}\right)}{\partial r}+\frac{1}{r} \frac{\partial w_{\theta}}{\partial \theta}+\frac{\partial w_{z}}{\partial z}\right]^{2}
\end{gathered}
$$

The practical application of the proposed Eq.(2) is limited by a complicated structure of this relation. Therefore, this relationship can be simplified to a more efficient form. It should be noticed that in this case the following assumptions are taken into consideration:

- $\quad$ for cylindrical coordinates

$$
r=\left[0, r_{0}\right] ; \quad \theta=[0,2 \pi] ; \quad z=[0, L]
$$

- $\quad$ for the steady-state of heat transfer process

$$
\frac{\partial T(t ; r, \theta, z)}{\partial t}=0 ; \quad \frac{\partial p(t ; r, \theta, z)}{\partial t}=0
$$

- $\quad$ for the incompressible fluid

$$
\operatorname{div} \bar{w}(r, \theta, z)=0
$$

- for physical parameters of the fluid are calculated for the averaged temperature of the mixed liquid

$$
\left(\rho, c_{p}, \eta, k\right)=f\left(\left[T_{i n}\right]_{a v g}\right)
$$

- $\quad$ for the axial symmetry of the fluid flow

$$
(T, \bar{w}, p) \neq f(\theta) ; \quad w_{r}=0 \quad \text { if } \quad r=0 \wedge r=r_{0}
$$

- $\quad$ for the pressure drop in the radial direction

$$
\frac{\partial p}{\partial r} \cong 0
$$

- $\quad$ for the temperature of steam (heating medium) 


$$
T_{\text {steam }}=\text { const }
$$

- $\quad$ for the velocity (the $z$ coordinate represents the main flow direction)

$$
w_{z}=f(\dot{m})
$$

- for the temperature

$$
T(r, z)=f(\dot{m}, r, z)
$$

- $\quad$ for the pressure

$$
p(z)=f(\dot{m}, z)
$$

- $\quad$ for the temperature driving force

$$
\Delta \widetilde{T_{i n}}(\dot{m}, r, z)=\left[\widetilde{T_{w, i n}}(\dot{m}, r, z)-\widetilde{T_{i n}}(\dot{m}, r, z)\right]
$$

- $\quad$ for the viscous dissipation function $\Phi_{V}$

$$
\Phi_{V}=0
$$

The proposed Eq.(2) may be simplified satisfying the proposed assumptions and conditions (see Eqs (4a-4l)). Thus, the rewritten form of Eq.(2) in the cylindrical coordinate system may be expressed as follows

$$
\begin{gathered}
\rho c_{p} w_{r} \frac{\partial \widetilde{T_{i n}}(\dot{m}, r, z)}{\partial r}+\rho c_{p} w_{z}(\dot{m}) \frac{\partial \widetilde{T_{i n}}(\dot{m}, r, z)}{\partial z}=k\left(\frac{\partial^{2} \widetilde{T_{i n}}(\dot{m}, r, z)}{\partial r^{2}}+\frac{1}{r} \frac{\partial \widetilde{T_{i n}}(\dot{m}, r, z)}{\partial r}\right)+ \\
+k \frac{\partial^{2} \widetilde{T_{i n}}(\dot{m}, r, z)}{\partial z^{2}}+w_{z}(\dot{m}) \frac{\partial p(\dot{m}, z)}{\partial z}
\end{gathered}
$$

taking into account the mass flow rate $m$.

The graphical presentation of the obtained Eq.(5) is presented in Fig.1. 


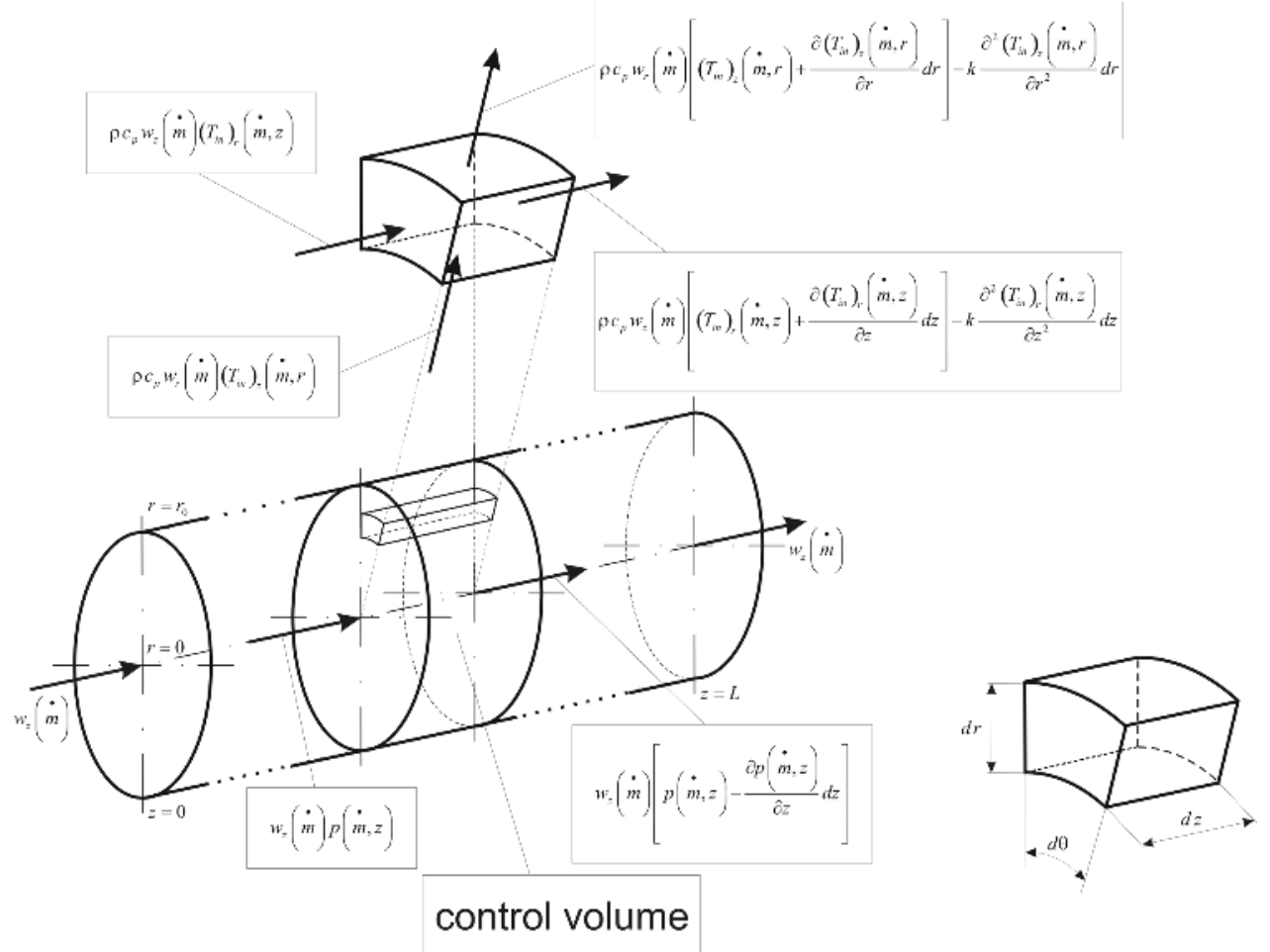

Figure 1. Graphical presentation of Eq.(5)

The term $k\left(\frac{\partial^{2} \widetilde{T_{i n}}(\dot{m}, r, z)}{\partial r^{2}}+\frac{1}{r} \frac{\partial \widetilde{T_{i n}}(\dot{m}, r, z)}{\partial r}\right)$ in the above Eq.(5) represents the heat conduction in the radial direction. This term may be defined by means of the heat transfer coefficient as follows

$$
\begin{gathered}
\left\{\int_{0}^{r_{0}} k\left[\frac{\partial^{2} \widetilde{T_{i n}}(\dot{m}, r, z)}{\partial r^{2}}+\frac{1}{r} \frac{\partial \widetilde{T_{i n}}(\dot{m}, r, z)}{\partial r}\right] d r=\int_{0}^{r_{0}} \partial\left(k r \frac{\partial \widetilde{T_{i n}}(\dot{m}, r, z)}{\partial r}\right) d r=\left.k r \frac{\partial \widetilde{T_{i n}}(\dot{m}, r, z)}{\partial r}\right|_{r=0} ^{r=r_{0}}\right\}= \\
=r_{0} h(\dot{m})\left[\widetilde{T_{i n}}(\dot{m}, r, z)\right]_{\text {avg }}
\end{gathered}
$$

Taking into consideration the above relation (Eq.(6)) and the definition of the averaged temperature driving force 


$$
\left[\widetilde{T_{\text {in }}}(\dot{m}, r, z)\right]_{\text {avg }}=\frac{\int_{0}^{r_{0}} w_{r} \widetilde{T_{i n}}(\dot{m}, r, z) r d r}{\int_{0}^{r_{0}} w_{r} r d r}
$$

we obtain the following form of Eq.(6)

$$
\begin{gathered}
r_{0} h(\dot{m}) \frac{\int_{0}^{r_{0}} w_{r} \widetilde{T_{i n}}(\dot{m}, r, z) r d r}{\int_{0}^{r_{0}} w_{r} r d r}=-\int_{0}^{r_{0}} \rho c_{p} w_{r} \frac{\partial \widetilde{T_{i n}}(\dot{m}, r, z)}{\partial r} r d r- \\
+\int_{0}^{r_{0}}\left[\rho c_{p} w_{z}(\dot{m}) \frac{\partial \widetilde{T_{i n}(\dot{m}, r, z)}}{\partial z}-k \frac{\partial^{2} \widetilde{T_{i n}}(\dot{m}, r, z)}{\partial z^{2}}\right] r d r+\int_{0}^{r_{0}} w_{z}(\dot{m}) \frac{\partial p(\dot{m}, z)}{\partial z} r d r
\end{gathered}
$$

According to the established conditions (Eqs (4a-4l)) the first term of the right side of Eq.(8) is defined as follows

$$
\int_{0}^{r_{0}} \rho c_{p} w_{r} \frac{\partial \widetilde{T_{i n}}(\dot{m}, r, z)}{\partial r} r d r=0
$$

Moreover, the integral $\int_{0}^{r_{0}} \widetilde{T_{i n}}(\dot{m}, r, z) r d r$ in Eq.(8) may be expressed in the following form (for $r \in\left(0, r_{0}\right)$ )

$$
\int_{0}^{r_{0}} \widetilde{T_{i n}}(\dot{m}, r, z) r d r=T_{w, i n}\left(\dot{m}, r=r_{0}, z\right)-T_{\text {in }}\left(\dot{m}, r=r_{0}, z\right) \Rightarrow \widetilde{T_{i n}}(\dot{m}, z)
$$

Introducing relations (9) and (10) in the Eq.(8) gives the differential form of the energy balance equation

$$
\frac{2}{r_{0}} h(\dot{m}) \widetilde{T_{i n}}(\dot{m}, z)=-\rho c_{p} w_{z}(\dot{m}) \frac{\partial \widetilde{T_{i n}(\dot{m}, z)}}{\partial z}+k \frac{\partial^{2} \widetilde{T_{i n}(\dot{m}, z)}}{\partial z^{2}}+w_{z}(\dot{m}) \frac{\partial p(\dot{m}, z)}{\partial z}
$$

The dependence of the liquid density on the temperature may be taken into consideration by applying the following expression 


$$
\rho\left(\widetilde{T_{i n}}(\dot{m}, z)\right)=\rho\left(1+\beta \widetilde{T_{\text {in }}}(\dot{m}, z)\right)
$$

Then, Eq.(11) may be written as follows

$$
\begin{aligned}
& \frac{2}{r_{0}} h(\dot{m}) \widetilde{T_{i n}}(\dot{m}, z)= \\
& =-\rho\left(1+\beta \widetilde{T_{i n}}(\dot{m}, z)\right) c_{p} w_{z}(\dot{m}) \frac{\partial \widetilde{T_{i n}}(\dot{m}, z)}{\partial z}+k \frac{\partial^{2} \widetilde{T_{i n}}(\dot{m}, z)}{\partial z^{2}}+w_{z}(\dot{m}) \frac{\partial p(\dot{m}, z)}{\partial z}
\end{aligned}
$$

The governing Eq.(13) may be rewritten in a symbolic shape which is useful for a dimensionless analysis. The introduction of non-dimensional quantities denoted by sign $(*)$ into this relationship yields

$$
\begin{gathered}
\left(2 \frac{h_{0} \widetilde{T_{i n_{0}}}}{r_{0}}\right)\left[h^{*}(\dot{m}) \widetilde{T_{i n}}(\dot{m}, z)\right]= \\
=-\left(\frac{\rho_{0} c_{p_{0}} w_{z_{0}} \widetilde{T_{i n_{0}}}}{l_{0}}+\frac{\rho_{0} \beta_{0} \widetilde{T_{i n_{0}}} c_{p_{0}} w_{z_{0}} \widetilde{T_{i n_{0}}}}{l_{0}}\right)\left[\rho^{*}\left(1+\beta^{*}{\widetilde{T_{i n}}}^{*}(\dot{m}, z)\right) c_{p}^{*} w_{z}^{*}(\dot{m}) \frac{\partial \widetilde{T_{i n}} \cdot(\dot{m}, z)}{\partial z^{*}}\right]+ \\
+\left(\frac{k_{0} \widetilde{T_{i n_{0}}}}{l_{0}^{2}}\right)\left[k^{*} \frac{\partial^{2} \widetilde{T_{i n}}(\dot{m}, z)}{\partial z^{*} \partial z^{*}}\right]+\left(\frac{w_{z_{0}} \Delta p_{0}}{l_{0}}\right)\left[w_{z}^{*}(\dot{m}) \frac{\partial p^{*}(\dot{m}, z)}{\partial z^{*}}\right]
\end{gathered}
$$

The temperature $\widetilde{T_{i n_{0}}}$ in the above Eq.(14) is defined by using the following relationship

$$
\frac{1}{l_{0}} \int_{0}^{l_{0}} \widetilde{T_{i n}}(\dot{m}, z) d z=\widetilde{T_{i n_{0}}}(\dot{m}) \Rightarrow \widetilde{T_{i n_{0}}}
$$

The non-dimensional form of Eq.(14) may be scaled against the convective term $\left(\frac{k_{0} \widetilde{T_{i n_{0}}}}{l_{0}^{2}}\right)$. The dimensionless form of this equation includes the following dimensionless groups characterizing the heat transfer process in a static mixer

$$
\left(2 \frac{h_{0} \widetilde{T_{i n_{0}}}}{r_{0}} \cdot \frac{l_{0}^{2}}{k_{0}} \widetilde{T_{i n_{0}}}\right) \Rightarrow\left(4 \frac{h_{0} d_{0}}{k_{0}}\left(\frac{l_{0}}{d_{0}}\right)^{2}\right) \Rightarrow 4 \mathrm{Nu}\left(\frac{l_{0}}{d_{0}}\right)^{2}
$$




$$
\begin{aligned}
& \left(\frac{\rho_{0} c_{p_{0}} w_{z_{0}} \widetilde{T_{i n_{0}}}}{l_{0}} \cdot \frac{l_{0}^{2}}{k_{0} \widetilde{T_{i n_{0}}}}+\frac{\rho_{0} \beta_{0} \widetilde{T_{i n_{0}}} c_{p_{0}} w_{z_{0}} \widetilde{T_{i n_{0}}}}{l_{0}} \cdot \frac{l_{0}^{2}}{k_{0} \widetilde{T_{i n_{0}}}}\right) \Rightarrow\left(\frac{\rho_{0} c_{p_{0}} w_{z_{0}} l_{0}}{k_{0}}+\frac{\rho_{0} \beta_{0} \widetilde{T_{i n_{0}}} c_{p_{0}} w_{z_{0}} l_{0}}{k_{0}}\right) \Rightarrow \\
& \Rightarrow\left(\frac{\rho_{0} w_{z_{0}} d_{0}}{\eta_{0}} \cdot \frac{c_{p_{0}} \eta_{0}}{k_{0}} \cdot \frac{l_{0}}{d_{0}}+\frac{\rho_{0}^{2} \beta_{0} g_{0} \widetilde{T_{i n_{0}}} l_{0}^{3}}{\eta_{0}^{2}} \cdot \frac{\eta_{0}}{\rho_{0} w_{z_{0}} d_{0}} \cdot \frac{w_{z_{0}}^{2}}{g_{0} l_{0}} \cdot \frac{c_{p_{0}} \eta_{0}}{k_{0}} \cdot \frac{d_{0}}{l_{0}}\right) \Rightarrow \\
& \Rightarrow\left(\operatorname{Re} \operatorname{Pr} \frac{l_{0}}{d_{0}}\left(1+\frac{\mathrm{GrFr}}{\operatorname{Re}^{2}}\left(\frac{d_{0}}{l_{0}}\right)^{2}\right)\right) \\
& \left(\frac{w_{z_{0}} \Delta p_{0}}{l_{0}} \cdot \frac{l_{0}^{2}}{k_{0} \widetilde{T}_{i n_{0}}}\right) \Rightarrow\left(\frac{\Delta p_{0}}{\rho_{0} w_{z_{0}}^{2}} \cdot \frac{\eta_{0} w_{z_{0}}^{2}}{k_{0} \widetilde{T}_{i n_{0}}} \cdot \frac{\rho_{0} w_{z_{0}} d_{0}}{\eta_{0}} \cdot \frac{l_{0}}{d_{0}}\right) \Rightarrow\left(\operatorname{EuBr} \operatorname{Re}\left(\frac{l_{0}}{d_{0}}\right)\right)
\end{aligned}
$$

Taking into account the proposed relations (16a)-(16c), we find the following dimensionless governing equation

$$
\begin{gathered}
\left(4 \mathrm{Nu}\left(\frac{l_{0}}{d_{0}}\right)^{2}\right)\left[h^{*}(\dot{m}) \widetilde{T_{i n}^{*}}(\dot{m}, z)\right]= \\
=-\left(\operatorname{Re} \operatorname{Pr} \frac{l_{0}}{d_{0}}\left(1+\frac{\mathrm{Gr} \operatorname{Fr}}{\operatorname{Re}^{2}}\left(\frac{d_{0}}{l_{0}}\right)^{2}\right)\right)\left[\rho^{*}\left(1+\beta^{*}{\widetilde{T_{i n}}}^{*}(\dot{m, z})\right) c_{p}^{*} w_{z}^{*}(\dot{m}) \frac{\partial \widetilde{T_{i n}}(\dot{m}, z)}{\partial z^{*}}\right]+ \\
+\left[k^{*} \frac{\partial^{2} \widetilde{T_{i n}^{*}}(\dot{m}, z)}{\partial z^{*} \partial z^{*}}\right]+\left(\operatorname{EuBr} \operatorname{Re}\left(\frac{l_{0}}{d_{0}}\right)\right)\left[w_{z}^{*}(\dot{m}) \frac{\partial p^{*}(\dot{m}, z)}{\partial z^{*}}\right]
\end{gathered}
$$

The above non-dimensional relationship (see Eq.(17)) is obtained by means of a scaling analysis. Scaling means non-dimensionalization of an equation describing the system under study. In this case this technically simple procedure is applied in order to obtain a dimensionless equation and relations between relevant dimensionless numbers, which are used to describe the effects of power characteristics on the heat transfer process in a motionless mixing device. It should be noticed that the proposed dimensionless equation (see Eq.(17)) has certain advantages, such as: the obtained dimensionless numbers are relevant for the analysed problem, the proportion between the individual terms may be established and the relationships that indicate the relevant proportions between these terms may be worked out.

It should be noticed that the proposed Eq.(17) consists of the combinations of the dimensionless numbers containing the heat transfer and the mixing process. The complex structure of this relation results from the combination of momentum and heat transports in 
a static mixer. Moreover, the establishment of the new criterion for the selection of a static mixer in heat transfer investigations is available by using the elaborated form of Eq.(17). The dimensionless numbers or their combinations may be used for making correlations, which are commonly used for design, scale-up and optimization purposes. In these correlations, some quantities or effects may be neglected. Moreover, the proposed correlations are presented as a linear relation between complex dimensionless terms.

From the dimensionless form of Eq.(17) it follows that the dimensionless Nusselt number (this number is commonly applied to the correlations for the heat transfer problems) may be separately compared with the dimensionless numbers terms. It should be noticed that the Nusselt number estimates the heat passing through the interface without computing the temperature and velocity fields. Therefore, the relationships obtained for the analysed problem may be expressed in the following form taking into account that the term $\left(\operatorname{EuBr} \operatorname{Re}\left(\frac{l_{0}}{d_{0}}\right)\right)$ is neglected

$$
\begin{gathered}
\left(\mathrm{Nu}\left(\frac{l_{0}}{d_{0}}\right)^{2}\right) \propto\left(\operatorname{Re} \operatorname{Pr} \frac{l_{0}}{d_{0}}\left(1+\frac{\mathrm{GrFr}}{\operatorname{Re}^{2}}\left(\frac{d_{0}}{l_{0}}\right)^{2}\right) \Rightarrow \mathrm{Nu} \propto \operatorname{Re} \operatorname{Pr} \frac{d_{0}}{l_{0}}\left(1+\frac{\operatorname{GrFr}}{\operatorname{Re}^{2}}\left(\frac{d_{0}}{l_{0}}\right)^{2}\right) \Rightarrow\right. \\
\Rightarrow \mathrm{Nu} \propto \operatorname{Pe} \frac{d_{0}}{l_{0}}\left(1+\frac{\operatorname{GrFr}}{\operatorname{Re}^{2}}\left(\frac{d_{0}}{l_{0}}\right)^{2}\right)
\end{gathered}
$$

or when the term $\left(\operatorname{Re} \operatorname{Pr} \frac{l_{0}}{d_{0}}\left(1+\frac{\operatorname{Gr} \operatorname{Fr}}{\operatorname{Re}^{2}}\left(\frac{d_{0}}{l_{0}}\right)^{2}\right)\right)$ is neglected

$$
\begin{gathered}
\left(\operatorname{EuBr} \operatorname{Re}\left(\frac{l_{0}}{d_{0}}\right)\right) \propto\left(\operatorname{Re} \operatorname{Pr} \frac{l_{0}}{d_{0}}\left(1+\frac{\operatorname{GrFr}}{\operatorname{Re}^{2}}\left(\frac{d_{0}}{l_{0}}\right)^{2}\right)\right) \Rightarrow \operatorname{Eu} \propto \frac{\operatorname{Re} \operatorname{Pr}}{\operatorname{Br} \operatorname{Re}}\left(1+\frac{\operatorname{Gr} \operatorname{Fr}}{\operatorname{Re}^{2}}\left(\frac{d_{0}}{l_{0}}\right)^{2}\right) \Rightarrow \\
\Rightarrow \operatorname{Eu} \propto \frac{\operatorname{Pe}}{\operatorname{Br}}\left(\frac{1}{\operatorname{Re}}+\frac{\operatorname{GrFr}}{\operatorname{Re}^{3}}\left(\frac{d_{0}}{l_{0}}\right)^{2}\right)
\end{gathered}
$$

When the operational objective is the heat transfer process the key parameter may be defined as follows

$$
\begin{gathered}
\varepsilon=\frac{\dot{Q}}{N} \Rightarrow \varepsilon=\frac{h F \widetilde{T_{\text {in }}}}{\dot{V \Delta p}} \Rightarrow \varepsilon=\frac{\pi d l h \widetilde{T_{\text {in }}}}{\frac{\pi d^{2}}{4} w \Delta p} \Rightarrow \varepsilon=4\left(\frac{h d}{k}\right) \cdot\left(\frac{\rho w^{2}}{\Delta p}\right) \cdot\left(\frac{k \widetilde{T_{i n}}}{\eta w^{2}}\right) \cdot\left(\frac{\eta}{\rho w d}\right) \cdot\left(\frac{l}{d}\right) \Rightarrow \\
\Rightarrow \varepsilon=4 \frac{\mathrm{Nu}}{\operatorname{EuBrRe}}\left(\frac{l}{d}\right)
\end{gathered}
$$


The proposed criterion (see Eq.(20)) takes both the heat transfer enhancement and the pressure drop into account. According to the obtained Eq.(17), we find the following relationship

$$
\begin{gathered}
\left(4 \mathrm{Nu}\left(\frac{l_{0}}{d_{0}}\right)^{2}\right) \propto\left(\operatorname{EuBr} \operatorname{Re}\left(\frac{l_{0}}{d_{0}}\right)\right) \Rightarrow 4 \mathrm{Nu}\left(\frac{l_{0}}{d_{0}}\right)^{2}=\varepsilon \operatorname{EuBr} \operatorname{Re}\left(\frac{l_{0}}{d_{0}}\right) \Rightarrow \\
\Rightarrow \varepsilon=4 \frac{\mathrm{Nu}}{\operatorname{EuBr} \operatorname{Re}}\left(\frac{l_{0}}{d_{0}}\right)
\end{gathered}
$$

It should be noticed that the proposed criterion $\varepsilon$ (see Eq.(21)) is worked out by applying the theoretical analysis of the non-dimensional form of Eq.(17). The proposed parameter $\varepsilon$ may be used as a criterion suitable for the applications of static mixers as the heat exchangers. Form the theoretical point of view, this criterion is dependent on hydrodynamic conditions (the dimensionless Reynolds number) and the real effect of viscous dissipation on the heat transfer process (the dimensionless Brinkman number). Table 1 summarizes all the essential and independent dimensionless numbers given in Eqs (17-21).

\section{Experimental details}

\subsection{Experimental investigations of pressure drop in static mixers}

Experimental studies of the pressure drop device were carried out using the static mixer experimental set-up shown in Fig.2.

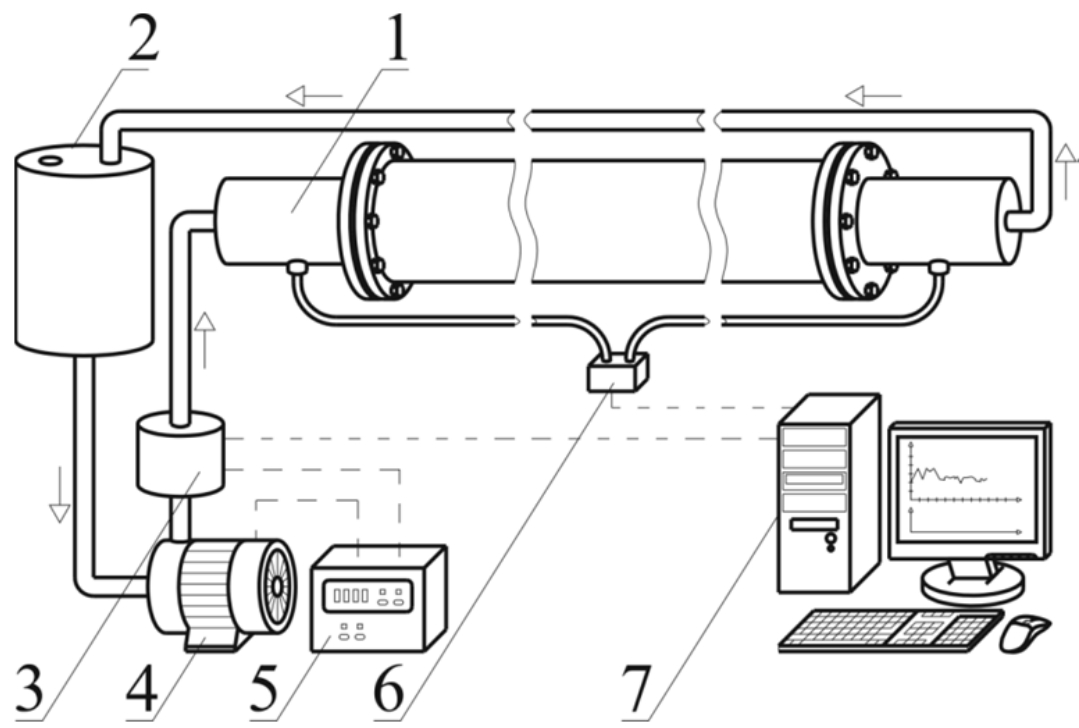

Figure 2. Sketch of experimental set-up: 1 - static mixer, 2 - storage vessel, 3 - electromagnetic flow meter, 4 - circulating pump, 5 - electronic control box, 6 - pressure drop converter FCX-C, 7 - personal computer 


\begin{tabular}{|c|c|c|c|c|}
\hline Name & Symbol & Definition & Significance & $\begin{array}{c}\text { Interpretation and } \\
\text { Remarks } \\
\end{array}$ \\
\hline Brinkman & $\mathrm{Br}$ & $\frac{\eta_{0} w_{z_{0}}^{2}}{k_{0} \widehat{T_{i n_{0}}}}$ & $\frac{\text { momentum transfer }}{\text { conductive heat transfer }}$ & $\begin{array}{l}\text { Dimensionless number } \\
\text { related from a wall to a } \\
\text { flowing fluid. This number } \\
\text { is a measure of the } \\
\text { importance of the viscous } \\
\text { heating relative the } \\
\text { conductive heat transfer. }\end{array}$ \\
\hline Euler & $\mathrm{Eu}$ & $\frac{\Delta p_{0}}{\rho_{0} w_{z_{0}}^{2}}$ & $\frac{\text { pressure force }}{\text { inertial force }}$ & $\begin{array}{l}\text { It express the relationship } \\
\text { between a local pressure } \\
\text { drop and the kinetic } \\
\text { energy. }\end{array}$ \\
\hline Froude & $\mathrm{Fr}$ & $\frac{w_{z_{0}}^{2}}{g_{0} l_{0}}$ & $\frac{\text { inertial force }}{\text { gravitational force }}$ & $\begin{array}{c}\text { Dimensionless number } \\
\text { defined as a ratio of } \\
\text { characteristic velocity to a } \\
\text { gravitational wave } \\
\text { velocity. }\end{array}$ \\
\hline Grashof & $\mathrm{Gr}$ & $\frac{\rho_{0}^{2} \beta_{0} g_{0} \widetilde{T_{i n_{0}}} l_{0}^{3}}{\eta_{0}^{2}}$ & $\frac{\text { buoyancy force }}{\text { viscous force }}$ & $\begin{array}{l}\text { It approximates the ratio of } \\
\text { the buoyancy to viscous } \\
\text { force acting on a fluid. }\end{array}$ \\
\hline Nusselt & $\mathrm{Nu}$ & $\frac{h_{0} d_{0}}{k_{0}}$ & $\frac{\text { convective heat transfer }}{\text { conductive heat transfer }}$ & $\begin{array}{l}\text { This number is the ration } \\
\text { of convective to } \\
\text { conductive heat transfer } \\
\text { across the boundary. }\end{array}$ \\
\hline Péclet & $\mathrm{Pe}$ & $\frac{\rho_{0} w_{z_{0}} d_{0} c_{p_{0}}}{k_{0}}$ & $\frac{\text { rate of advection }}{\text { rate of diffusion }}$ & $\begin{array}{l}\text { This number is defined to } \\
\text { be the ratio of the rate of } \\
\text { advection to rate of } \\
\text { diffusion of the same } \\
\text { quantity driven by } \\
\text { appropriate gradient. The } \\
\text { presented number is } \\
\text { applied in the case of the } \\
\text { diffusion of heat (thermal } \\
\text { diffusion). }\end{array}$ \\
\hline Prandtl & $\operatorname{Pr}$ & $\frac{c_{p_{0}} \eta_{0}}{k_{0}}$ & $\frac{\text { momentum diffusivity }}{\text { thermal diffusivity }}$ & $\begin{array}{l}\text { It defines the ratio of } \\
\text { momentum diffusivity and } \\
\text { thermal diffusivity. }\end{array}$ \\
\hline Reynolds & $\operatorname{Re}$ & $\frac{\rho_{0} w_{z_{0}} d_{0}}{\eta_{0}}$ & $\frac{\text { inertial force / convection }}{\text { viscous force }}$ & $\begin{array}{c}\text { This number gives a } \\
\text { measure of the ratio of } \\
\text { inertial forces to viscous } \\
\text { forces. }\end{array}$ \\
\hline
\end{tabular}

Table 1. Dimensionless numbers in Eqs (15-19) and their physical role 
All the experimental work was performed using the static mixer in a horizontal tube closed on both ends by cylindrical caps. Inside the tube the mixing elements were placed to mix the flowing fluid. The cylindrical cups had central inlet and outlet valves. On the lower part of these cups the outlet valve and valves for the digital pressure drop converter FCX-CII (FHCV11V2-AKABY-AA, Fuji Electric France S.A., Clermont-Ferrand, France) were attached. This converter was used to measure the pressure drop of the fluid between the ends of the horizontal tube. On the upper part of the cylindrical cups venting valves was mounted. The experimental installation worked in a closed circuit. The mixed fluid (water) was sucked by a circulation pump from a buffer container and pumped through a flow meter to the tube of the static mixer. The fluid flow in the mixer's tube was measured by the electromagnetic flow meter (MPP-04, ENCO S.A., Warszawa, Poland) installed at the mixer's inlet.

\subsection{Experimental investigations of the heat transfer process in the static mixer}

The static mixer experimental set-up for the investigations of the heat transfer process is presented in Fig.3. This apparatus consists of an external heat exchanger, a circulating pump, an electrical steam generator and temperature sensors connected to a digital measuring equipment.

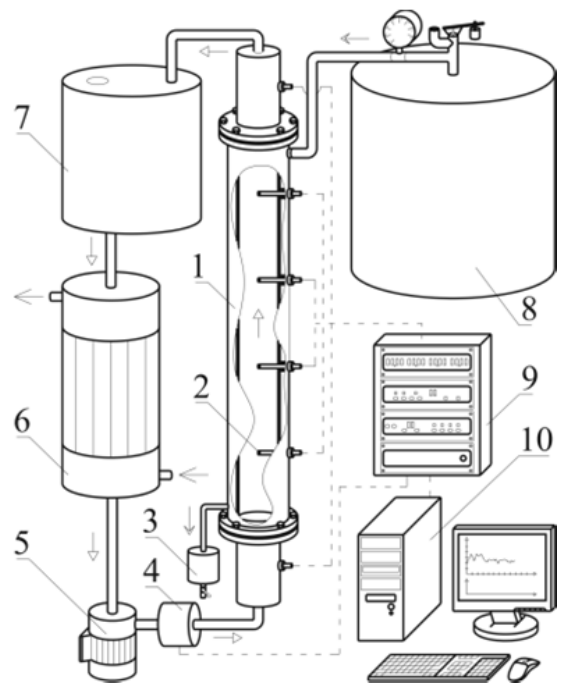

Figure 3. Static mixer of experimental set-up: 1 - static mixer with heating jacket,

2 - temperature sensors, 3 - condenser pot, 4 - electromagnetic flow meter,

5 - circulating pump, 6 - heat exchanger, 7 - storage vessel, 8 - steam generator,

9 - temperature sampling system, 10 - personal computer

The heat transfer enhancement was determined by measuring the profiles on each side of the heating pipe as well as the temperature field inside the static mixer. The heat from the condensing steam in the heating jacket was introduced to the flowing and mixed liquid by the novel mixing device. One system of the temperature sensors was tightened closely to 
both sides of the inner tube and other bunches of small sensors were placed inside the bulk of the static mixer. These sensors were used to measure the distribution of the mixer bulk temperature across the radius and the length of the inner tube. According to the theoretical consideration, the experimental investigations were realized for the steady-state condition of the heat transfer process. The measured temperature distribution was undertaken to determine the augmentation of the heat transfer by using the tested mixing device. Water was used as the liquid flowing through the inner pipe of the static mixer. The mass flow rate was measured by means of the electromagnetic flow-meter. The temperature within the mixed liquid varied significantly along the tube axis and increased much with the variation of the mass flow rate. The variations of the temperature in the cross section of the inner tube were so small, that the recorded distribution of the temperature might be accepted as no existing. The experimental set-up was equipped with a measuring instrument which controlled the temperature of the liquid and supervised the real-time acquisition of all the experimental data coming from the sensors. This device also measured the temperature fluctuations inside the static mixer during the process. Electric signals were sampled by using the special thermal sensors (LM-61B, National Semiconductor Corporation, Santa Clara, USA) and were passed through the converter (PCI-1710HG, Advantech, Milpitas, USA) to a personal computer for further processing.

\subsection{The applied type of motionless inserts (elements)}

Figure 4 shows schematic diagrams of motionless inserts used in the present work. The main purpose of these elements was to redistribute fluid in the radial and tangential directions transverse to the main flow. In the case of this experimental work, the enhancement of the heat transfer process was realized by applying the industrial mixing devices (EMI, Ross, Komax).

a)

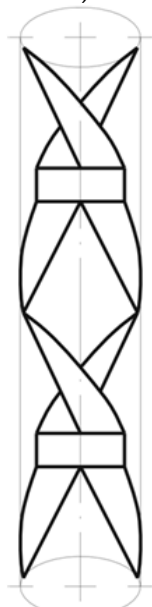

b)

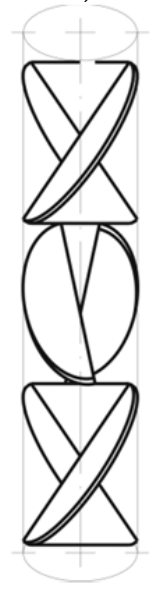

c)

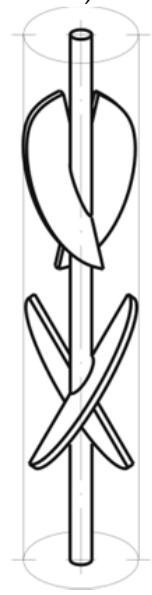

d)

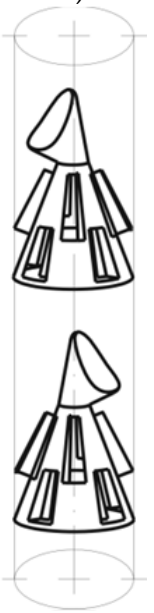

Figure 4. Applied motionless inserts: a) Komax, b) Ross, c) EMI, d) new type of mixing element 
Moreover, the measurements were also carried out with the static mixer equipped with a new mixing insert, which was a modified version of the mixer described in the patent registration (Masiuk \& Szymański, 1997) (see Fig.4d). The single mixing element had two truncated cones connected with each other. The diameter of the bigger cone was equal to the inner diameter of the apparatus. On the side surface of the inlet cone the longitudinal slots were placed symmetrically along the circumference. The slots were equipped with steering blades placed on their longitudinal edges. The side surface of the inlet cone had an oval shape near its lower base.

A stream of fluid flowing into the inlet cone was redistributed - the slots on the surface of the cone were steering the flow outside, while the steering blades bestowed the arising streams with the rotational movement. A part of the stream leaving the inside of the insert through the outlet cone became turbulent due to the cone's oval shape. The inner and outer streams were mixed before entering the next mixing element where the streams were redistributed once again, rotated in the opposite direction, and reconnected.

A novel mixing device was built up from five separate segments (see Fig.4d) in the form of two top opened cones. The large cone had longitudinal holes on the conical face with motionless outside baffles. The experiments were carried out with the cascade including 5 mixing elements. They were arranged in the tube of the static mixer along its full length. Neighbouring mixing elements differed in the spin direction of the blades and in the magnitude of the bulge of the outlet cone and were alternatively directed against each other. A good mixing and an increase of fluid homogeneity were achieved for the fluid that passed through the system of the mixing elements.

Table 2 gives the ranges of the operating conditions and the calculated dimensionless numbers for an empty duct and for static mixing elements.

\section{Results and discussion}

From the practical point of view the heat transfer problems may be modelled by means of the well-known Nusselt type equation

$$
\mathrm{Nu}=f(\operatorname{Re}, \operatorname{Pr})
$$

In the present report we consider the heat transfer in static mixers may be described by a similar but somewhat modified relationship between the dimensionless Nusselt number and the combination of numbers which were defined by the hydrodynamic effects in the tested experimental set-up containing different types of motionless devices.

The generalization of the results of the convective heat transfer measurements was correlated by using the worked out Nusselt-type equation (see Eq.(18)). It should be noticed that the proposed relation was obtained from the theoretical considerations. Therefore, the dependency $\mathrm{Nu} \propto \mathrm{Pe} \frac{d_{0}}{l_{0}}\left(1+\frac{\mathrm{GrFr}}{\operatorname{Re}^{2}}\left(\frac{d_{0}}{l_{0}}\right)^{2}\right)$ was gained as the linear relation. Evidently, 
The Effects of Power Characteristics on

the Heat Transfer Process in Various Types of Motionless Mixing Devices 361

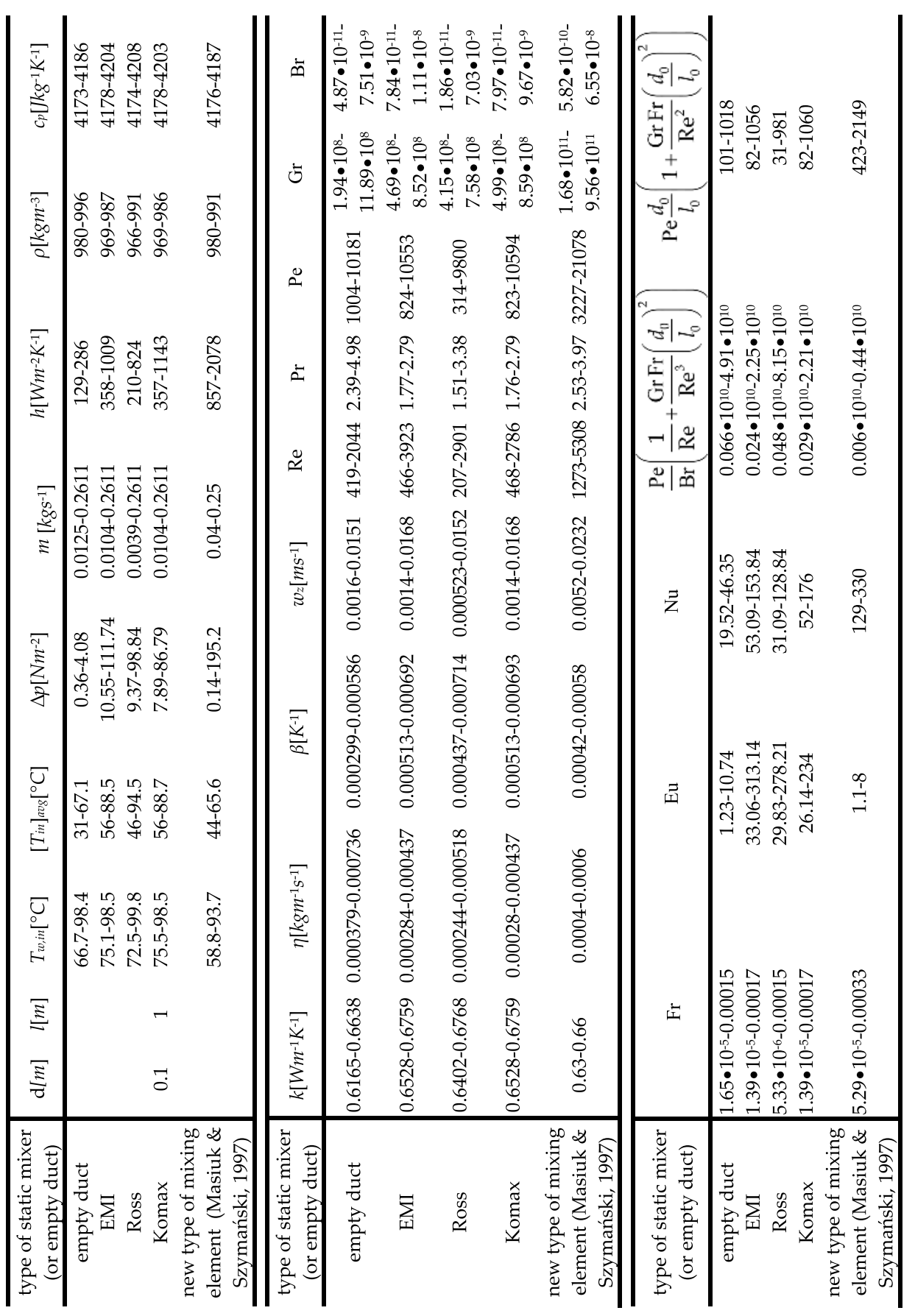

Table 2. The tabulated ranges of the operating conditions and the calculated dimensionless numbers 
a)

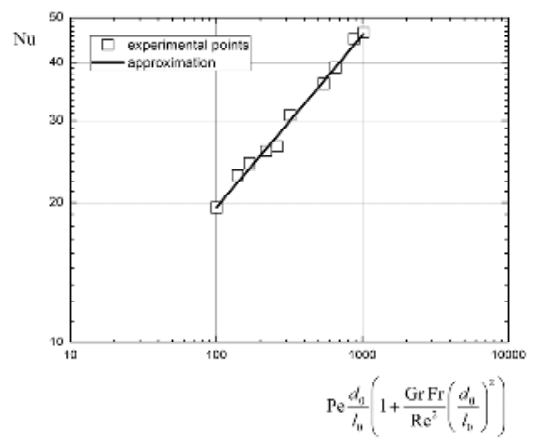

c)

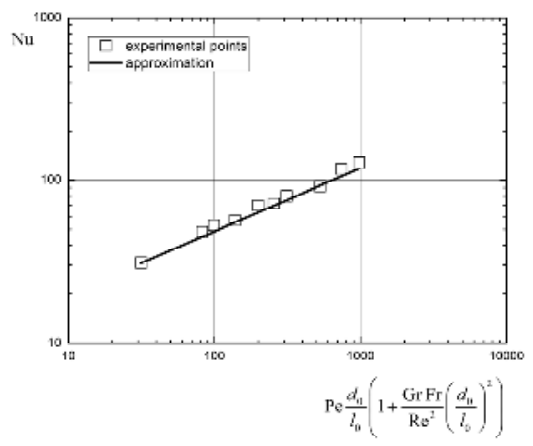

e)

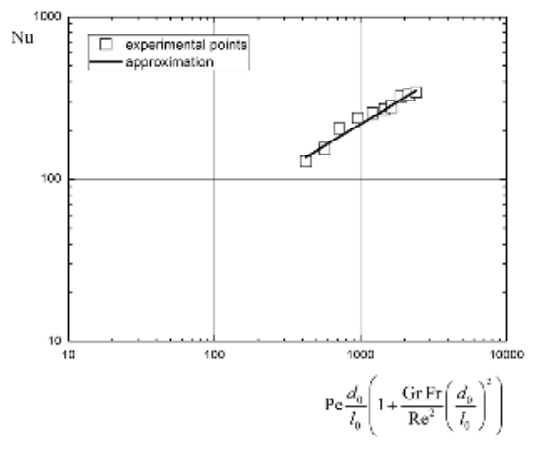

b)

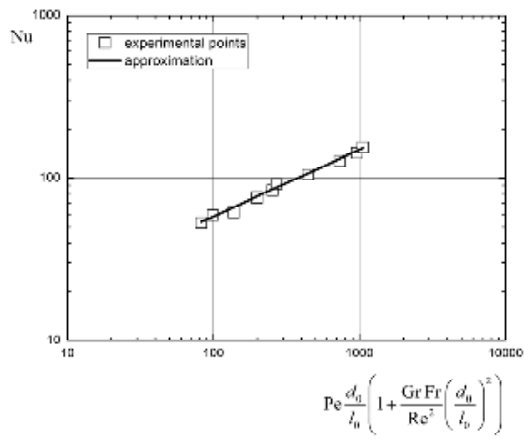

d)

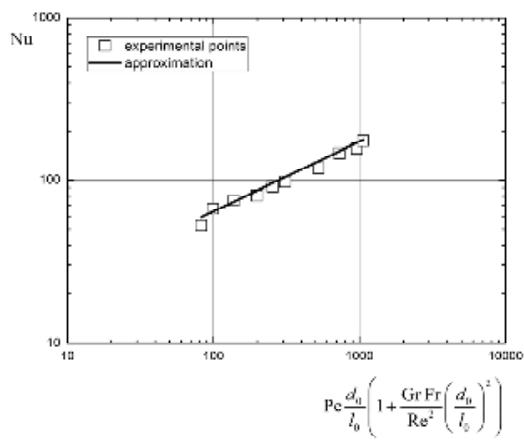

f)

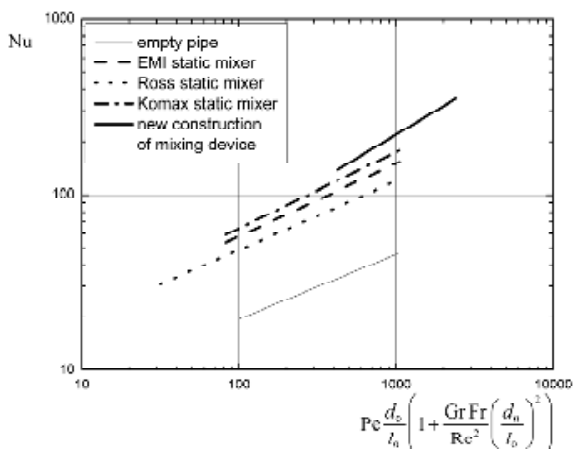

Figure 5. The generalization of the results of the convective heat transfer measurements: a) empty pipe, b) EMI static mixer, c) Ross static mixer, d) Komax static mixer, e) new construction of motionless mixing device, f) comparison of the heat transfer correlations for the different type of motionless mixing device

Eq.(18) must be rendered quantitatively to be practically used. This may be done by assuming that the functional relation is in the following form 


$$
\mathrm{Nu}=f\left[\operatorname{Pe} \frac{d_{0}}{l_{0}}\left(1+\frac{\operatorname{GrFr}}{\operatorname{Re}^{2}}\left(\frac{d_{0}}{l_{0}}\right)^{2}\right)\right] \Rightarrow \mathrm{Nu}=p_{1}\left[\operatorname{Pe} \frac{d_{0}}{l_{0}}\left(1+\frac{\operatorname{GrFr}}{\operatorname{Re}^{2}}\left(\frac{d_{0}}{l_{0}}\right)^{2}\right)\right]^{p_{2}}
$$

In order to establish the effect of the term $\left[\operatorname{Pe} \frac{d_{0}}{l_{0}}\left(1+\frac{\operatorname{GrFr}}{\operatorname{Re}^{2}}\left(\frac{d_{0}}{l_{0}}\right)^{2}\right)\right]$ on the dimensionless Nusselt number the experimental data obtained in this work are graphically illustrated in the log-log system in Fig. 5.

The experimental results shown in Fig.5a-5e suggest that the heat transfer process in various types of motionless inserts may be analytically described by a unique monotonic function (see Eq.(23)). The constants and exponents were computed by employing the Matlab software and the principle of least squares and the obtained values are collected in Table 3. The calculated values of the approximation errors $(M A E, M R E, M P E, \sigma, R)$ are also presented in this table.

\begin{tabular}{c|cc|ccccc}
\hline \multirow{2}{*}{ type of static mixer (or empty duct } & \multicolumn{3}{|c|}{ Eq.(23) } & \multicolumn{5}{c}{ approximation errors } \\
\cline { 2 - 8 } & $p_{1}$ & $p_{2}$ & $M A E$ & $M R E$ & $M P E$ & $\sigma$ & $R$ \\
\hline empty duct & 3.55 & 0.37 & 0.62 & 0.02 & $2.05 \%$ & 9.14 & 0.99 \\
EMI & 8.79 & 0.41 & 2.52 & 0.03 & $2.74 \%$ & 35.07 & 0.99 \\
Ross & 8.05 & 0.39 & 4.58 & 0.06 & $5.57 \%$ & 28.71 & 0.99 \\
Komax & 8.89 & 0.43 & 6.01 & 0.06 & $6.04 \%$ & 41.48 & 0.99 \\
new type of mixing element & 5.24 & 0.54 & 10.34 & 0.05 & $4.58 \%$ & 70.79 & 0.98 \\
(Masiuk \& Szymański, 1997) & & & & & & & \\
\hline
\end{tabular}

Table 3. The values of the parameters Eq.(23) with the list of approximation errors

It can be seen from Fig.5a-5e that the scatter of experimental points for various types of a motionless mixer may be described by the same type of relation (Eq.(23)) by using various values of the coefficients $p_{1}$ and $p_{2}$. It is clear that the heat transfer process is dependent on the geometrical configuration of the applied motionless insert. Therefore, the difference between coefficients in the proposed relation (23) (see Table 3) is due to different geometries of static mixers.

The enhancement of the heat transfer process can be attributed to the breakdown of the thermal boundary layer especially near the tube wall. It should be noticed that the enhancement is provided by the motionless mixer in which the higher heat flux or the heat transfer rate is achieved without the deterioration of the flowing fluid.

The comparison of the results of our own investigations is presented in Fig.5f. This figure shows that the significant enhancement in the heat transfer performance for the applied static mixers is obtained with respect to the empty tube. It can be seen that the values of the 
Nusselt number for the new type of the static mixer are greater than the values of this dimensionless number obtained in this work for different types of the motionless devices (EMI, Ross and Komax). It should be noticed that the incensement of the heat transfer ratio is connected with the flow regime. The observed discrepancies between the obtained heat transfer characteristics increase with the intensification of the hydrodynamic conditions expressed by the term $\left[\operatorname{Pe} \frac{d_{0}}{l_{0}}\left(1+\frac{\operatorname{GrFr}}{\operatorname{Re}^{2}}\left(\frac{d_{0}}{l_{0}}\right)^{2}\right)\right]$. The new construction of the mixing device is given a modest improvement in the heat transfer rate but it is achieved by higher values of the mentioned term. Thus, standard motionless mixers (EMI, Ross or Komax) may be more useful to enhnace the heat transfer process for a lower value of the term. As follows from the analysis of Fig.5f, the new construction of the motionless insert is more effective for the turbulent region of the fluid flow. This leads to the conclusion that the heat transfer rate is mainly dependent on the geometrical configuration of the motionless insert and the generated hydrodynamic conditions in the flowing fluid through the static mixer.

It should be noticed that the hydrodynamic conditions in motionless mixers are strongly dependent on the pressure drop. The pressure drop database may be directly correlated by using the friction factor or the ratio of friction factors. From the practical point of view, this database may be elaborated by using the dimensionless Euler number. It can avoid confusion when comparing the static mixer to the empty tube or different types of motionless devices.

In the present report, the pressure drop for different types of static mixers is described by the relationship between the dimensionless Euler number and the obtained complex of the dimensionless numbers (see Eq.(19)). Accordingly to the obtained relationship and the above considerations the experimental data may be worked out by means of the following relationship

$$
\mathrm{Eu}=f\left[\frac{\mathrm{Pe}}{\operatorname{Br}}\left(\frac{1}{\operatorname{Re}}+\frac{\mathrm{GrFr}}{\operatorname{Re}^{3}}\left(\frac{d_{0}}{l_{0}}\right)^{2}\right)\right] \Rightarrow \mathrm{Eu}=p_{3}\left[\frac{\operatorname{Pe}}{\operatorname{Br}}\left(\frac{1}{\operatorname{Re}}+\frac{\operatorname{GrFr}}{\operatorname{Re}^{3}}\left(\frac{d_{0}}{l_{0}}\right)^{2}\right)\right]^{p_{4}}
$$

Figure 6 illustrates the manner in which the Euler number varies in the operational range describing the term

$\left[\frac{\mathrm{Pe}}{\mathrm{Br}}\left(\frac{1}{\operatorname{Re}}+\frac{\mathrm{GrFr}}{\operatorname{Re}^{3}}\left(\frac{d_{0}}{l_{0}}\right)^{2}\right)\right]$. The dashed lines in Fig.6a-6e are calculated from the general Eq.(24), where the relation between the dimensionless numbers is obtained from the theoretical considerations. In the case of these experimental investigations, the established relation (24) was also proposed as a power function. This form is universally applied in the description of the heat and momentum transfer problem. 
a)

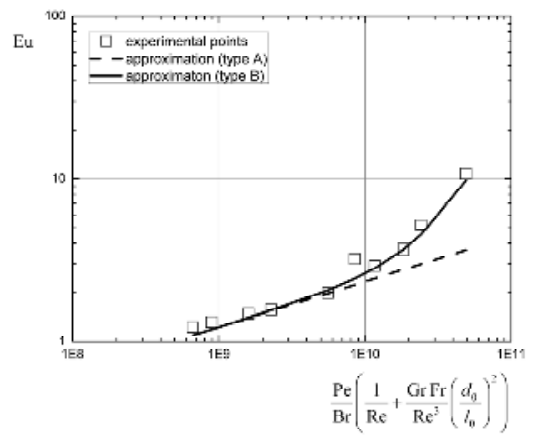

c)

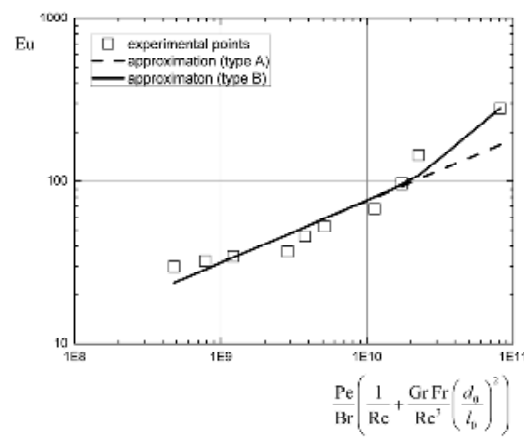

e)

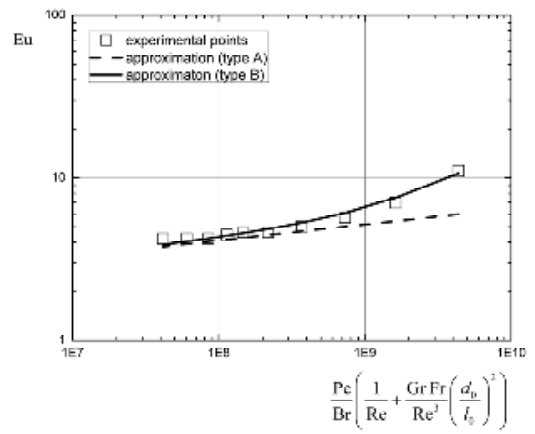

b)

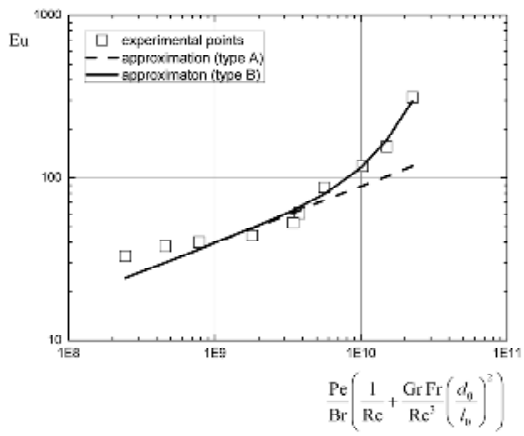

d)

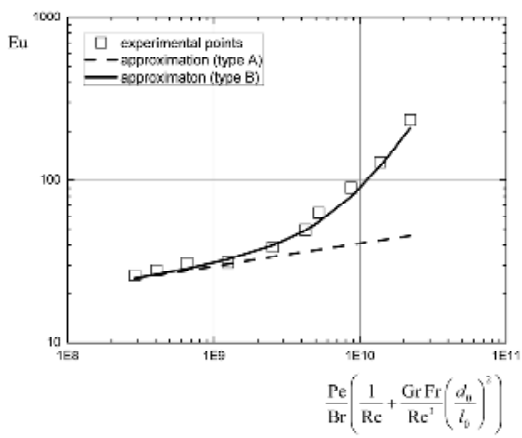

f)

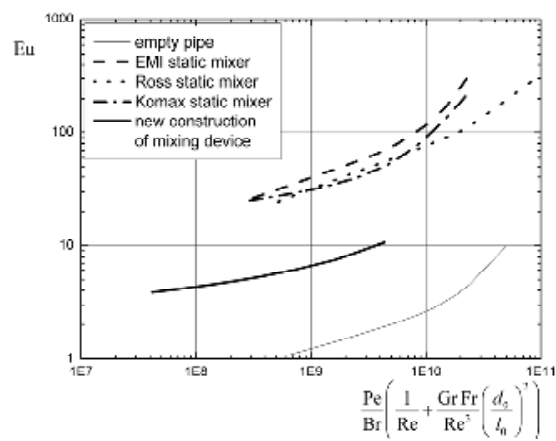

Figure 6. The generalization of the results of the power characteristic: a) empty pipe, b) EMI static mixer, c) Ross static mixer, d) Komax static mixer, e) new construction of motionless mixing device, f) comparison o the heat transfer correlations for the different type of motionless mixing device

The constants and exponents were computed by employing the Matlab software and the principle of least squares. The list of the parameter values $\left(p_{3}, p_{4}\right)$ and the calculated values of the approximated errors are tabulated in the table 4 (approximation type A in Fig.6). 


\begin{tabular}{c|cc|ccccc}
\hline \multirow{2}{*}{$\begin{array}{c}\text { type of static mixer (or empty } \\
\text { duct }\end{array}$} & \multicolumn{3}{|c|}{ Eq.(24) } & \multicolumn{5}{c}{ approximation errors } \\
\cline { 2 - 8 } & $p_{3}$ & $p_{4}$ & $M A E$ & $M R E$ & $M P E$ & $\sigma$ & $R$ \\
\hline empty duct & 0.004 & 0.28 & 1.21 & 0.21 & $21 \%$ & 2.16 & 0,88 \\
EMI & 0.03 & 0.35 & 31.05 & 0.13 & $13 \%$ & 65.62 & 0.89 \\
Ross & 0.012 & 0.38 & 19.99 & 0.04 & $3.57 \%$ & 61.91 & 0.92 \\
Komax & 1.63 & 0.14 & 37.59 & 0.31 & $30.59 \%$ & 49.29 & 0.85 \\
new type of mixing element & 0.65 & 0.10 & 0.93 & 0.13 & $12.62 \%$ & 1.61 & 0.91 \\
Masiuk \& Szymański, 1997) & & & & & & & \\
\hline
\end{tabular}

Table 4. The values of the parameters Eq.(24) with the list of approximation errors

As follows from the graphical presentation of the obtained results (see Fig.6a-6e) the power characteristic as the $\mathrm{Eu} \propto\left[\frac{\mathrm{Pe}}{\mathrm{Br}}\left(\frac{1}{\operatorname{Re}}+\frac{\mathrm{GrFr}}{\operatorname{Re}^{3}}\left(\frac{d_{0}}{l_{0}}\right)^{2}\right)\right]$ curve is a very curvilinear dependence. Initially, the results given in Fig.6a-6e indicate the enhancement in the dimensionless Euler number with an increase of the complex dimensionless numbers. Up to a certain critical value of this complex $\left(\left[\frac{\mathrm{Pe}}{\operatorname{Br}}\left(\frac{1}{\operatorname{Re}}+\frac{\operatorname{Gr} \operatorname{Fr}}{\operatorname{Re}^{3}}\left(\frac{d_{0}}{l_{0}}\right)^{2}\right)\right] \in\left(10^{9}, 10^{10}\right)\right)$, the experimental points follow a straight line and can be correlated by using the analytical description given by the proposed Eq.(24) (approximation type A in Fig.6).

It should be noticed that the dimensionless Euler number increases sharply with the increase of the complex dimensionless numbers and considerably higher increase takes place in the region of large values of this complex. The experimental results shown in Fig.6 suggest that the Euler number versus the mentioned term of the dimensionless relationship can be analytically described by a unique monotonic function including a special correction term. It should be noticed that the dimensionless Euler number versus $\left[\frac{\operatorname{Pe}}{\operatorname{Br}}\left(\frac{1}{\operatorname{Re}}+\frac{\operatorname{Gr} \operatorname{Fr}}{\operatorname{Re}^{3}}\left(\frac{d_{0}}{l_{0}}\right)^{2}\right)\right]$ term is described by a similar relationship that is proposed in the relevant literature (Masiuk, 2000; Masiuk, 1999; Masiuk \& Rakoczy, 2007). Then, the previously proposed relation may be adapted in the following general dimensionless correlation

$$
\mathrm{Eu}=p_{3}\left[\frac{\mathrm{Pe}}{\operatorname{Br}}\left(\frac{1}{\operatorname{Re}}+\frac{\mathrm{GrFr}}{\operatorname{Re}^{3}}\left(\frac{d_{0}}{l_{0}}\right)^{2}\right)\right]^{p_{4}}\left\{1+p_{5}\left[\frac{\operatorname{Pe}}{\operatorname{Br}}\left(\frac{1}{\operatorname{Re}}+\frac{\mathrm{GrFr}}{\operatorname{Re}^{3}}\left(\frac{d_{0}}{l_{0}}\right)^{2}\right)\right]^{p_{6}}\right\}
$$

The constants and exponents in the proposed relation (25) depend on the geometrical configuration of the motionless mixer and their values are collected in Table 5. 


\begin{tabular}{|c|c|c|c|c|c|c|c|c|c|}
\hline \multirow{2}{*}{$\begin{array}{l}\text { type of static mixer (or empty } \\
\text { duct }\end{array}$} & \multicolumn{4}{|c|}{ Eq.(25) } & \multicolumn{5}{|c|}{ approximation errors } \\
\hline & $p_{3}$ & $p_{4}$ & $p_{5}$ & $p_{6}$ & $M A E$ & $M R E$ & $M P E$ & $\sigma$ & $R$ \\
\hline empty duct & 0.004 & 0.28 & $3 \cdot 10^{-18}$ & 1.66 & 0.29 & 0.073 & $7.23 \%$ & 2.68 & 0.99 \\
\hline EMI & 0.03 & 0.35 & $3 \cdot 10^{-21}$ & 2 & 6.41 & 0.008 & $0.78 \%$ & 83.57 & 0.99 \\
\hline Ross & 0.012 & 0.38 & $1 \cdot 10^{-22}$ & 2 & 8.42 & 0.012 & $1.29 \%$ & 74.57 & 0.98 \\
\hline Komax & 1.63 & 0.14 & $\begin{array}{c}1.5 \cdot 10^{-} \\
14\end{array}$ & 1.39 & 5.56 & 0.049 & $4.91 \%$ & 60.51 & 0.99 \\
\hline $\begin{array}{l}\text { new type of mixing element } \\
\text { (Masiuk \& Szymański, 1997) }\end{array}$ & 0.65 & 0.10 & $0.9 \cdot 10^{-7}$ & 0.72 & 0.23 & 0.008 & $0.82 \%$ & 2.061 & 0.99 \\
\hline
\end{tabular}

Table 5. The values of the parameters Eq.(25) with the list of approximation errors

Figure 6 also illustrates the graphical forms of the above Eq.(25) for the tested motionless mixers as the full curves marked by the solid lines (approximation type B). Fig.6 demonstrates that, within scatter limits among the plotted data represented by the points, the dimensionless Euler number increases with the increase of the mentioned complex term. The first conclusion drawn from the inspection of this graph is that the proposed relationship in a general form of Eq.(25) fits the analysed experimental data very well. One of the advantages of the elaborated relation is the possibility to apply it to generalize the experimental results in the whole range of the fluid flow. It should be noticed that the complex form of the proposed relationship (Eq.(25)) results from the obtained hydrodynamic conditions for the analysed static mixers.

The comparison of the obtained results for various types of the motionless mixers is presented in Fig.6f. This figure shows that the calculated values of the dimensionless Euler number are strongly dependent on the term $\left[\frac{\operatorname{Pe}}{\operatorname{Br}}\left(\frac{1}{\operatorname{Re}}+\frac{\operatorname{GrFr}}{\operatorname{Re}^{3}}\left(\frac{d_{0}}{l_{0}}\right)^{2}\right)\right]$. This plot also confirms that the geometrical configuration of the motionless insert has a significant effect on the pressure drop expressed as the mentioned non-dimensional number. It should be noticed that the pressure drop is the most important design criterion for a motionless mixer. It permits to quantify the disspated power in this mixer type. Moreover, the pressure drop expressed as the dimensionless Euler number is also a decisive factor for the estimation of the efficiency of motionless mixers. This number is dependent on several parametrs, such as: flow rates, the type of fluid and the geometrical configuration of a motionless insert of a static mixer (e.g. type, number or arrangements of element of this type of mixer).

In this case study, the pressure drops were measured for various types of static mixers. As follows from Fig.6f the power characteristic for the new type of the mixing device is similar to the power characteristic for practically used motionless devices. As can be seen from this figure, there is a significant difference between the dimensionless Euler numbers for the tested static mixers. It can be seen that the dimensionless Euler number increases slightly with increasing complex $\left[\frac{\operatorname{Pe}}{\operatorname{Br}}\left(\frac{1}{\operatorname{Re}}+\frac{\operatorname{Gr} \operatorname{Fr}}{\operatorname{Re}^{3}}\left(\frac{d_{0}}{l_{0}}\right)^{2}\right)\right]$. This figure illustrates an interesting 
feature that for the new type of the mixing device the enhancement of the dimensionless Euler number is much lower than for different types of static mixers. It is demonstrated that commonly applied mixing devices give a greater enhancement in the pressure drop than the new construction.

In the selection of suitable motionless mixing devices for the heat transfer process it is not sufficient to take into consideration the heat transfer ratio and the hydrodynamic conditions separately. The heat transfer encompasses the thermal homogenization and the heat exchange and the procedures for a heat exchanger design are not included in the estimation for the hydrodynamic conditions in the mixed liquid. In this experimental paper a new criterion (see Eq.(20) or (21)) is defined which takes both the heat transfer enhancement and the hydrodynamic conditions into account. The proposed criterion includes the rates of the heat transfer process and the hydrodynamic conditions. Therefore, the criterion $\varepsilon$ is defined as the ratio of the dimensionless Nusselt number to the product of the dimensionless Euler, Brinkman and Reynolds numbers.

This criterion may be used to the comparison of the influence of different types of motionless mixing devices on the heat transfer operations. The calculated value of the obtained criterion varies with the parameters of the mixing process and depends on the operating conditions and the physical properties of the liquid. This relationship can be expressed by the following general equation

$$
\varepsilon=f(N T U) \Rightarrow\left[4 \frac{\mathrm{Nu}}{\mathrm{EuBrRe}}\left(\frac{l_{0}}{d_{0}}\right)\right]=f\left[\frac{\pi d_{0} l_{0} h_{0}}{\dot{m} c_{p_{0}}}\right]
$$

The results of the measurements and calculations are presented in the form of a plot of the criterion versus NTU indication. The results presented in Fig.7 suggest that the proposed relation can be analytically described by a unique monotonic function. This results in an equation for the whole range of the NTU of the form

$$
\varepsilon=p_{9}(N T U)^{p_{10}}
$$

in which it is necessary to use different values of the exponents $p_{9}$ and $p_{10}$ for different types of motionless mixing devices. The constants and exponents are computed employing the principle of least squares.

The experimental results showed that the proposed criterion $\varepsilon$ increases when the NTU indication is increased in a wide range. The tested static mixers are highly effective during the heat transfer operation. As follows from the experimental results the heat transfer enhancement of the new construction of the mixing device is high without an excessive increase in the pressure drop. It is evident that the new type of the static mixer tends to be superior to a comparably different type over most of the operating range shown. 


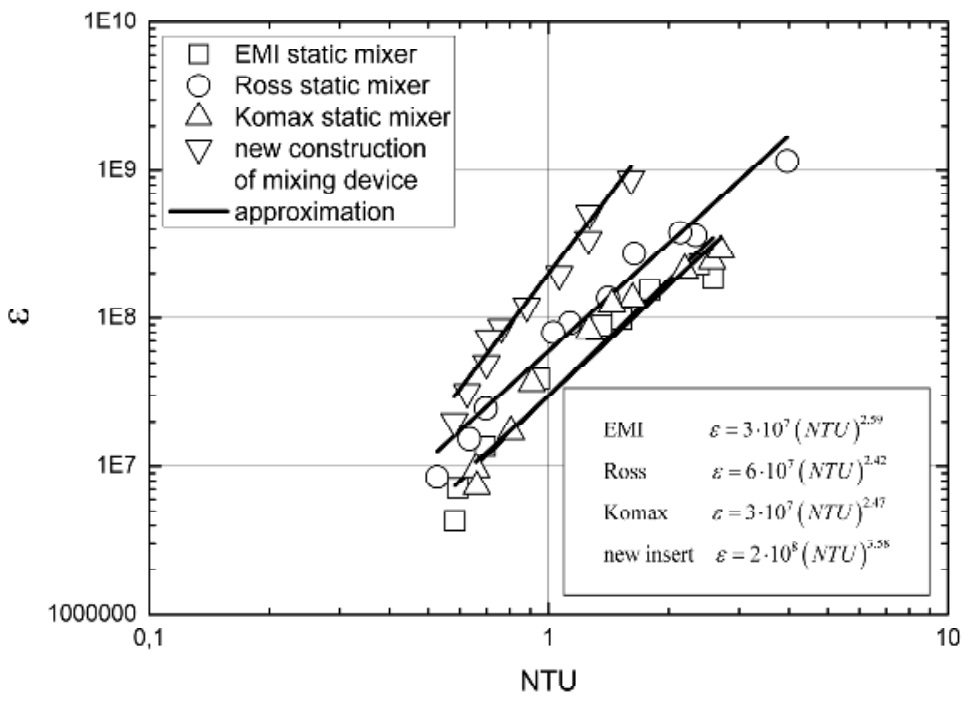

Figure 7. Comparison of the criterion $\varepsilon$ values for the different type of motionless mixing devices

\section{Conclusion}

Salient remarks resulting from the present investigation may be summarized as follows:

1. Various motionless mixing devices have different influence on the heat transfer process and the pressure drop enhancement.

2. The theoretical description of the problem and the equations predicted in the present article is much more attractive because it generalizes the experimental data of the heat transfer process (see Eq.(23)) and the pressure drop database (see Eq.(25)) taking into consideration various parameters in the form of the terms $\left[\operatorname{Pe} \frac{d_{0}}{l_{0}}\left(1+\frac{\operatorname{Gr} \operatorname{Fr}}{\operatorname{Re}^{2}}\left(\frac{d_{0}}{l_{0}}\right)^{2}\right)\right]$ or $\left[\frac{\operatorname{Pe}}{\operatorname{Br}}\left(\frac{1}{\operatorname{Re}}+\frac{\operatorname{GrFr}}{\operatorname{Re}^{3}}\left(\frac{d_{0}}{l_{0}}\right)^{2}\right)\right]$, respectively. The proposed new-type correlations should be adequate for design purposes when used within the range of experimental verification.

3. With respect to very useful criterions given in the literature which are singly obtained for static mixers it would be interesting to see the new general criterion related to this problem. From the practical point of view, this criterion may be used to the selection of a static mixer for the heat transfer problems.

4. The criterion $\varepsilon$ may be used to the comparison of the influence of different types of motionless mixing devices on the heat transfer operations with respect to the hydrodynamic conditions. 


\section{Nomenclature}

$\begin{array}{lll}c_{p} & - & \text { specific heat, } \mathrm{J} \cdot \mathrm{kg}^{-1} \cdot \mathrm{K}^{-1} \\ d & - & \text { pipe (mixer) diameter, } \mathrm{m} \\ F & - & \text { surface, } \mathrm{m}^{2} \\ \mathrm{~g} & - & \text { gravitional acceleration, } \mathrm{m} \cdot \mathrm{s}^{-2} \\ h & - & \text { heat transfer coefficient, } \mathrm{J} \cdot \mathrm{m}^{-2} \cdot \mathrm{K}^{-1} \cdot \mathrm{s}^{-1} \\ k & - & \text { thermal conductivity, } \mathrm{J} \cdot \mathrm{m}^{-1} \cdot \mathrm{K}^{-1} \cdot \mathrm{s}^{-1} \\ l & - & \text { mixer length, } \mathrm{m} \\ \dot{m} & - & \text { mass flow rate, } \mathrm{kg} \cdot \mathrm{s}^{-1} \\ N & - & \text { power, } \mathrm{J} \cdot \mathrm{s}^{-1} \\ p & - & \text { pressure, } \mathrm{kg} \cdot \mathrm{m}{ }^{-1} \cdot \mathrm{s}^{-2} \\ \Delta p & - & \text { pressure drop in static mixer, } \mathrm{kg} \cdot \mathrm{m}^{-1} \cdot \mathrm{s}^{-2} \\ \dot{Q} & - & \text { heat transfer rate, } \mathrm{J} \cdot \mathrm{s}^{-1} \\ r & - & \text { radial cylindrical coordinate, } \mathrm{m} \\ R & - & \text { correlation coefficient } \\ t & - & \text { time, } \mathrm{s} \\ T & - & \text { temperature, }{ }^{0} \mathrm{C} \\ T_{i n} & - & \text { temperature of flowing and mixed liquid, }{ }^{0} \mathrm{C} \\ T_{w, i n} & - & \text { inside wall temperature, }{ }^{0} \mathrm{C} \\ {\left[T_{i n}\right]_{a v g}} & - & \text { average value of liquid inside temperature, }{ }^{0} \mathrm{C} \\ \bar{w} & - & \text { velocity vector, } \mathrm{m} \cdot \mathrm{s}^{-1} \\ w_{r} & - & \text { radial component of liquid velocity, } \mathrm{m} \cdot \mathrm{s}^{-1} \\ w_{z} & - & \text { axial component of liquid velocity, } \mathrm{m} \cdot \mathrm{s}^{-1} \\ V & - & \text { volume of the static mixer, } \mathrm{m}^{3} \\ Z & - & \text { axial cylindrical coordinate, } \mathrm{m} \\ V & - & \text { volumetric flow rate, } \mathrm{m}^{3} \cdot \mathrm{s}^{-1} \\ & & \end{array}$

\section{Greek symbols}

$\begin{array}{lll}\beta & - & \text { coefficient of thermal expansion, } \mathrm{K}^{-1} \\ \varepsilon & - & \text { thermal-power efficiency criterion } \\ \eta & - & \text { liquid viscosity, } \mathrm{kg} \cdot \mathrm{m}^{-1} \cdot \mathrm{s}^{-1} \\ \eta_{V} & - & \text { volumetric viscosity ("second viscosity" }), \mathrm{kg} \cdot \mathrm{m}^{-1} \cdot \mathrm{s}^{-1} \\ \rho & - & \text { liquid density, } \mathrm{kg} \cdot \mathrm{m}^{-3} \\ \Phi_{V} & - & \text { viscous dissipation function, } \mathrm{kg} \cdot \mathrm{m}^{-1} \cdot \mathrm{s}^{-3}\end{array}$




\section{Dimensionless numbers}

$\begin{array}{lll}\mathrm{Br} & - & \text { Brinkman number } \\ \mathrm{Eu} & - & \text { Euler number } \\ \mathrm{Fr} & - & \text { Froude number } \\ \mathrm{Gr} & - & \text { Grashof number } \\ \mathrm{Nu} & - & \text { Nusselt number } \\ \mathrm{Pe} & - & \text { Péclet number } \\ \mathrm{Pr} & - & \text { Prandtl number } \\ \mathrm{Re} & - & \text { Reynolds number }\end{array}$

\section{Superscripts}

* - dimensionless value

\section{Subscripts}

$\begin{array}{lll}\text { steam } & - & \text { heating medium } \\ \text { in } & - & \text { Inside } \\ \text { avg } & - & \text { average value } \\ 0 & - & \text { reference value }\end{array}$

\section{Abbreviations}

$\begin{array}{lll}M A E & - & \text { mean approximation error } \\ M P E & - & \text { mean percentage error } \\ M R E & - & \text { mean relative error } \\ N T U & - & \text { number of transfer units }\end{array}$

\section{Author details}

Rafał Rakoczy, Marian Kordas and Stanisław Masiuk Institute of Chemical Engineering and Environmental Protection Process, West Pomeranian University of Technology, Poland

\section{Acknowledgement}

This work was supported by the Polish Ministry of Science and Higher Education from sources for science in the years 2012-2013 under Inventus Plus project

\section{References}

Al Taweel, A.M.; Azizi, J.Y.F.; Odedra, D. \& Gomma, H.G. (2005). Using in-line static mixers to intensity gas-liquid mass transfer processes. Chemical Engineering Science, Vol.60, pp. 6378-6390 
Engler, M.; Kockmann, N.; Kiefer, T. \& Woias, P. (2004). Numerical and experimental investigations on liquid mixing in static micromixers. Chemical Engineering Journal, Vol.101, pp. 315-322

Fourcade, E.; Wadely, R.; Hoefsloot, H.C.J.; Green, A. \& Iedema, P.D. (2001). CFD calculation of laminar striation thinning in static mixer reactors. Chemical Engineering Science, Vol.56, pp. 6729-6741

Hobbs, D.M.; Swanson, P.D. \& Muzzio, F.J. (1998). Numerical characterization of low Reynolds number flow in the Kenics static mixer. Chemical Engineering Science, Vol.53, pp. 1565-1584

Joshi, P.; Nigam, K.D.P. \& Nauman, E.B. (1995). The Kenics static mixer: new data and proposed correlations. Chemical Engineering Journal, Vol.59, pp. 265-271

Kumar, V.; Shirke, V. \& Nigam, K.D.P. (2008). Performance of Kenics static mixer over a wide range of Reynolds number. Chemical Engineering Journal, Vol.139, pp. 284-295

Lemenand, T.; Durandal, C.; Valle, D.D. \& Peerhossaini, H. (2010). Turbulent direct-contact heat transfer between two immiscible fluids. International Journal of Thermal Science, Vol.49, pp. 1886-1898

Li, H.Z.; Fasol, C. \& Choplin, L. (1997). Pressure drop of newtonian and non-newtonian fluids across a Sulzer SMX static mixer. Trans IChemE, Vol.75, pp. 792-796

Li, H.Z.; Fasol, Ch. \& Choplin, L. (1996). Hydrodynamics and heat transfer of rheologically complex fluids in a Sulzer SMX static mixer. Chemical Engineering Science, Vol.51, pp. 1947-1955

Liu, S.; Hrymak, A.N. \& Wood, P.E. (2006). Laminar mixing of shearing thinning fluids in a SMX static mixer. Chemical Engineering Science, Vol.61, pp. 1753-1759

Masiuk, S. \& Rakoczy, R. (2007). Power consumption, mixing time, heat and mass transfer measurements for liquid vessels that are mixed using reciprocating multiplates agitators. Chemical Engineering and Processing, Vol.46, pp. 89-98

Masiuk, S. \& Szymański, E. (1997). Static mixing device, Polish Patent PL No. 324150

Masiuk, S. (1999). Power consumptions measurements in a liquid vessel that is mixed using a vibratory agitator. Chemical Engineering Journal, Vol.75, pp. 161-165

Masiuk, S. (2000). Mixing time for a reciprocating plate agitator with flapping blades. Chemical Engineering Journal, Vol.79, pp. 23-30

Rama Rao, N.V.; Baird, M.H.I.; Hrymak, A.M. \& Wood, P.E. (2007). Dispersion of highviscosity liquid-liquid systems by flow through SMX static mixer elements. Chemical Engineering Science, Vol.62, pp. 6885-6895

Regner, M.; Östergren, K. \& Trägårdh, C. (2005). An improved numerical method of calculating the striation thinning in static mixers. Computers and Chemical Engineering, Vol.30, pp. 376-380

Ruivo, R.; Paiva, A. \& Simões, P.C. (2006). Hydrodynamics and mass transfer of a static mixer at high pressure conditions. Chemical Engineering and Processing, Vol.45, pp. 224-231

Simões, P.C.; Afonso, B.; Fernandes, J. \& Mota, J.P.B. (2008). Static mixers as heat exchangers in supercritical fluid extraction processes. Journal of Supercritical Fluids, Vol.43, pp. 477-483

Thakur, R.K.; Vial, Ch.; Nigam, K.D.P.; Nauman, E.B. \& Djelveh, G. (2003). Static mixers in the process industries - A review. Trans IChemE, Vol.81, pp. 787-826

Visser, J.E.; Rozendal, P.F.; Hoogstraten, H.W. \& Beenckers, A.A.C.M. (1999). Threedimensional numerical simulation of flow and heat transfer in the Sulzer SMX static mixer. Chemical Engineering Science, Vol.54, pp. 2491-2500 